\title{
The Role of Internal Customer in Improving the Quality of Hotel Services in Jordan: A Case Study of the Marriott International Hotel in
} Amman

\author{
Ali Falah Al-Zoubi ${ }^{1} \&$ Mazen Alomari ${ }^{2}$ \\ ${ }^{1}$ Marketing Department, Faculty of business, Arab Amman University, Jordan \\ ${ }^{2}$ Accounting Department, Faculty of business, Arab Amman University, Jordan \\ Correspondance: Ali Falah Al-Zoubi, Marketing Department, Faculty of Business, Arab Amman University, \\ Amman, Jordan. E-mail: alzoubifali@yahoo.com
}

Received: October 7, 2017

Accepted: November 27, 2017 Online Published: November 29, 2017

doi:10.5539/ijms.v9n6p82

URL: http://doi.org/10.5539/ijms.v9n6p82

\begin{abstract}
The present study aims to examine the role of internal customer in improving the quality of hotel services in order to provide distinguished and high-quality hotel services seeking to gain the satisfaction of the hotel customers in the light of local and international competition. This study also focused on the internal customer represented by hotel staff from various levels of employment through a set of independent variables such as selection, training, motivation and participation in decision making for improving the quality of hotel services. The sample of this study includes all directors (13) and employees (44) from different parts of the Marriott International Hotel in Amman. The study instrument was designed as a questionnaire for collecting data which consisted of (35) paragraphs according to five- dimensional scale of Likert. In addition, this study used Statistical Package for the Social Sciences (SPSS) to test the hypotheses. The most important findings and recommendations of the present study were that the management officials of the Marriott International Hotel in Amman should develop their knowledge and skills in terms of interest in the internal customers and gain a future vision to determine their needs of human resources and that there is a significant positive relationship between the role of internal customer and the improvement of the quality of hotel services.
\end{abstract}

Keywords: internal customer, hotel services, quality of services, Amman, Jordan

\section{Introduction}

Hotel industry is one of the main fundamentals of the national economy and a major resource that feeds the state treasury with foreign and local currencies. It can also activate other economical sectors, such as transport of all kinds, tourism and travel agencies, various types of shops, banks, insurance organizations, entertainment houses and other sectors related to tourism. In addition, it is one of the solutions for unemployment and providing labor. Thus, the development of tourism sector, in general, and hotel sector, in particular, has become of interest to the most of countries worldwide. This will be achieved by improving hotel services, as quality is an important element that must be paid attention to achieve high levels of performance. Therefore, attention must be paid to develop internal customers' skills in all departments who deal with each other to accomplish work; this includes co-workers, operations officers, production team, account management. If the internal customer is not satisfied with the services, the hotel will not be able to satisfy the external customer. So, at various levels of management, attention should be given to meet the needs of internal customers in order to improve their performance to be able to provide outstanding services that meet the needs and expectations of external customers.

The nature of relationship between the service organization, including hotels, and its customers is the delivery of promises through external marketing programs that they seek to achieve their satisfaction and meet their needs. The degree of an organization's credibility of the fulfillment of its promises depends on the extent to which the organization seeks to meet the needs and achieve satisfaction of its employees because they are who will carry out these promises. This can easily be achieved if the organization adopts the concept of 'Internal Marketing' and treats its employees as internal customers who should be given sufficient attention, as will be seen through this study. 


\section{General Framework of the Study}

\subsection{Problem of the Study}

The problem of study is the lack of interest in the hotel sector, in particular, to satisfy the internal customer, which negatively affects the level of satisfaction of the external customer that led to poor quality of hotel services provided to guests, and not focusing on subject all providers of these services to continuous training. Consequently, this negatively affects the hotel sector and tourism sector in general. With this in mind, this study aims to shed light on the impact of evaluating the role of the internal customer or employee in developing and improving the level of quality of hotel services provided to customers in order to meet their needs and achieve their satisfaction. For that reason, the problem of the study arises in the following main question: What is the relationship between the internal customer and improving the quality of hotel services at the Marriott International Hotel in Amman (Jordan)?

\subsection{Questions of the Study}

The problem of the study was focused on the following main question: What is the relationship between the internal customer and improving the quality of hotel services at the Marriott International Hotel in Amman? It gives rise to several sub-questions:

Q1: What is the relationship between internal customer's selection and training and improving the quality of hotel services provided in the Marriott International Hotel in Amman?

Q2: What is the relationship between motivating the internal customer and improving the quality of the provided hotel services?

Q3: How relevant is the decision-making involvement of the internal customer in improving the provided hotel services?

\subsection{Significance of the Study}

Due to the importance of quality of services in success of hotel business and the achievement of profits required, the challenge for managers to improve the quality of hotel services provided to external customers is to develop the performance and skills of internal customers as service providers. It is natural that no business organization can seek excellence in providing its products and services, without improving the level of its employees who are known as internal customers. In fact, this study dealt with a vital sector of hotel industry. In addition, the present study dealt with the internal customer relationship in improving the quality of hotel services at the Marriott International Hotel in Amman.

\subsection{Purpose of the Study}

The present study aims to highlight the role of internal customer in improving the quality of hotel services and the importance of developing the internal customer's skills and performance at the Marriott International Hotel in order to improve the quality of services provided to the external customer to achieve the objectives of the Hotel.

\subsection{Model and Variables of the Study}

This study includes a set of variables: the independent variable, the internal marketing with its dimensions, and the dependent variable, the quality of hotel services. The following figure illustrates this:

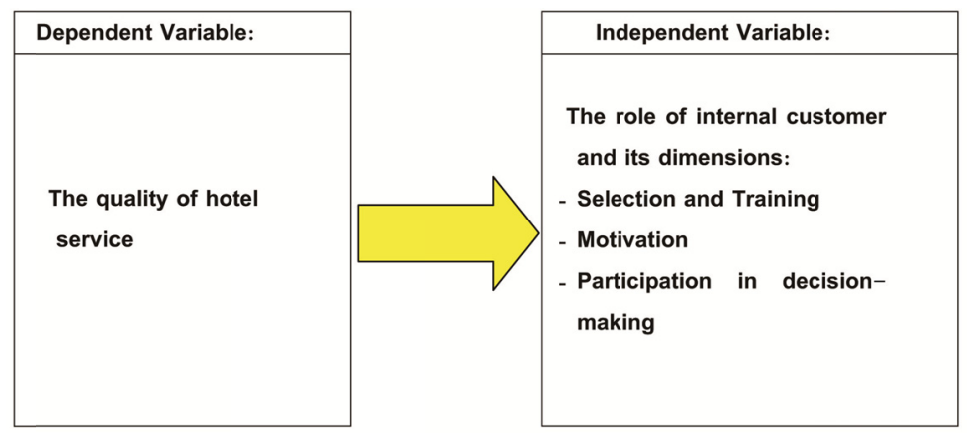

Figure 1. Model of the study

Source: (prepared by the researchers, 2017). 


\subsection{Hypotheses of the Study}

To solve the problem of the study and answer its questions, the following hypotheses were formulated:

- The main hypotheses: There is no significant role at the level of $(\alpha=0.05)$ of the internal customer with its dimensions (selection and training, motivation, participation in decision-making) in improving the quality of hotel services at the Marriott International Hotel in Amman. The following sub- hypotheses emerge from this main hypothesis:

- The first sub-hypothesis: There is no significant role at $(\alpha=0.05)$ for internal customer is training in improving the quality of hotel services provided in the Marriott International Hotel in Amman.

- The second sub-hypothesis: There is no significant role at $(\alpha=0.05)$ of motivating the internal customer in improving the quality of hotel services at the Marriott International Hotel in Amman.

- The third sub-hypothesis: There is no significant role at $(\alpha=0.05)$ of the internal customer's participation in decision-making in improving the quality if hotel services at the Marriott International Hotel in Amman.

\subsection{Methodology}

\subsubsection{Study Methodology}

This study was based on the analytical descriptive approach to conduct the field study and distribute the questionnaires to the sample members in order to collect and analyze data to answer the questions and test the hypotheses using the statistical program SPSS.

\subsubsection{Study Population}

The study was limited to all employees in Amman Marriott Hotel.

\subsubsection{Study Sample}

The study included (57) employees (13 managers and 44 employees).

\subsubsection{Statistical Methods Used in the Study}

The Statistical Package for Social Sciences (SPSS) was used in different statistical analyzes, within a set of statistical methods that were used to test the hypotheses of the study as follows:

-Alpha Cronbach's stability coefficient to identify the internal consistency of expressions.

-Kolmogorov-Smirnov (K-S) Test was used to test the extent to which data are following the normal distribution in a way that enables the application of the used statistical methods.

-Frequency distribution and percentages to describe the personal characteristics of the sample members of the study.

-The arithmetic mean as an indicator to the responses of the sample members and the standard deviation for measuring the degree of dispersion from arithmetic mean.

-Coefficient of correlation to measure the relationship between the variables of the study and One Way ANOVA to measure the effect of the independent variable on the dependent variable.

\subsubsection{Instrument of the Study}

A questionnaire was designed for data collection. It was designed according to the problem of the study and its variables. It was then drafted in final form after being arbitrated by a number of specialists. It consists of (35) items that included the variables of the study according to Likert's Five Scale as follows: The independent variable: the role of the internal customer with its dimensions (selection and training, motivation, participation in decision- making) and the dependent variable: the quality of the provided hotel services.

\subsubsection{Validity of Study Instrument}

To verify the validity of the instrument, the questionnaire was presented to a number of specialized arbitrators, where they had some points of view and observations, mostly focused on the wording of the paragraphs, and the modification of some terms to be more clear and accurate. Also, a preliminary study was conducted on a number of internal customers at the Hotel to ascertain the clarity of the statements contained in the questionnaire, and whether it was able to measure the variables of the study as a whole or not. 


\subsubsection{Reliability of Study Instrument}

To ensure the reliability of the instrument, Cronbach's Alpha coefficient was used to measure the level of reliability of the measuring instrument in terms of internal consistency of expressions. The results were as shown in the following table:

Table 1. Cronbach's Alpha coefficient for measuring the reliability of the study variables

\begin{tabular}{lll}
\hline Questionnaire's Variables & No. of paragraphs & Value of Cronbach's Alpha \\
\hline $\begin{array}{l}\text { The independent variable: The internal customer with its dimensions } \\
\text { (selection\& training, motivation, participation in decision-making). }\end{array}$ & & 0.823 \\
The dependent variable: The quality of the provided hotel services. & 18 & 0.853 \\
Total & 35 & 0.909 \\
\hline
\end{tabular}

Source: prepared by the researchers based on SPSS Version 19.

Through the above table, we note that the value of Cronbach's Alpha coefficient for the whole questionnaire is high (91\%). Therefore, the study instrument has a high degree of reliability that justifies its use for the purposes of the study as it exceeded the statistically acceptable percent.

To ensure that the data are normally distributed, we use the Normal Distribution Test for the data of the study variables (K.S).

- The independent variable: the hotel's interest in the internal customer's needs.

- Ho: Data of the first axis are not subjected to normal distribution.

- $\quad \mathrm{H}_{1:}$ Data of the first axis are subjected to normal distribution.

- The dependent variable: the hotel's interest in improving the quality of the provided hotel services.

- Ho: Data of the second axis are not subjected to normal distribution.

- $\quad \mathrm{H}_{1:}$ Data of the second axis are subjected to normal distribution.

Table 2. Normality distribution test of the data of the study variables (K-S test)

\begin{tabular}{llc}
\hline Questionnaire's Variables & K-S Test Value & Sig. \\
\hline $\begin{array}{l}\text { The independent variable: The role of the internal customer with its dimensions (selection\& } \\
\text { training, motivation, participation in decision-making) }\end{array}$ & 0.635 & 0.814 \\
The dependent variable: The quality of the provided hotel services & 0.699 & 0.714 \\
\hline
\end{tabular}

Source: prepared by the researchers based on SPSS Version 19.

It is clear from the previous table that the level of significant for each of the two axes is greater than 0.05 . Thus, the null hypothesis is rejected where the alternative hypothesis is accepted, and the data of both axes follow the normal distribution, enabling us to use laboratory tests.

\subsection{Limitations of the Study}

- Place limitations: The Marriott International Hotel.

- Time limitations: The study was carried out in the period from April 1 to May 31, 2017.

- Human limitations: The study was limited to internal customers (managers and employees in different departments of the Hotel).

- Objective limitations: The knowledge about the role of the internal customer and the quality of hotel services.

\subsection{Literature Review}

Several studies tackle one or more aspects of paying attention to human resources in hotels and their role in improving the quality of hotel services. The following are the most important previous studies that have examined this topic:

1) Sulaiman Al-Khattab et al. (2016), "The Impact of the Relationship between the Quality of Internal and External Service and Internal Customer Satisfaction as a Modified Variable: A study on a sample of Restaurants with Full Services in Amman". The aim of this study was to investigate the relationship between the quality of internal and external services for a group of restaurants with integrated services in Amman, and to examine the 
impact of internal customer's satisfaction (employees/ workers) as a modified variable and its impact on the external quality of services provided to customers. To achieve the objectives of this study, two forms of questionnaires were formulated: The first was prepared for the internal customer to measure and examine the dimensions of internal quality, which included (9) dimensions. A total of 200 questionnaires were distributed, 170 of them were retrieved and valid for analysis, i.e., $85 \%$ of them, which is suitable for analysis. The second form was designed for examining the dimensions of external quality, which was distributed to customers who visited the restaurant, which included (6) dimensions. A total of 450 questionnaires were distributed, 320 of them were retrieved and analyzed: $71 \%$ of the total distributed, and were suitable for analysis and statistical test. The study concluded that the most influential internal dimensions on the external quality are reliability, security and empathy. In addition, the results showed that the internal customer's satisfaction has a significant impact on enhancing the internal quality and thus its reflection on the external quality provided to customers.

2) Noureddin (2007), "The Quality of Services and its impact on Customers' Satisfaction: Field Study at the Enterprise Port of Skikda". The main objective of this study was to provide a theoretical framework that determines and defines the different quality concepts as a modern administrative approach. This study also focused mainly on the quality of services in terms of indicators and models that we divide. In addition, it examined the customer's listening system as a source for understanding the needs and expectations of customers. In turn, it is possible to identify the activities that lead to customer satisfaction. This study also discussed methods of measuring customer satisfaction to determine the degree of customer satisfaction with the services provided by the institution in order to find ways to improve the quality of services. In this field study, the researcher tried to analyze the contribution of the service quality assessment process to the satisfaction of the customers. The researcher examined the quality management system applied in the institution and its contribution to the achievement of quality in services. In addition, this study aimed to identify the approved ways in the institution to listen to the customer and how to measure customer satisfaction. This study found that customer evaluation of the quality of services through special evaluation indicators differs from one customer to another and that the quality of service works to achieve customer satisfaction.

3) Atilla Akbaba (2006), "Measuring Service Quality in the Hotel Industry: A Study in a Business Hotel in Turkey". This study aimed to examine the expectations of quality of service in hotels from the customers' point of view, and to investigate whether the quality dimensions included in the SERVQUAL Model are used in the international environment as well as to examine other dimensions that should be included in establishing the quality of service. In addition, it sought to measure the level of importance of each dimension for commercial hotels' customers. The study concluded that many business travelers had high expectations of the quality of hotel services provided according to the five dimensions of quality specified in the study. In addition, the use of SERVQUAL scale is a very useful tool for measuring the quality of hotel services.

4) Saffar \& Majda (2008), "the impact of applying the Philosophy of Total Quality Management According to internal and external customer perspectives on the Operational Performance of Manufacturing Organizations: A Case Study at Petra Engineering Industries Co. in Jordan". The objective of this study was to identify the impact of applying TQM philosophy according to internal and external customer perspectives on the operational performance of manufacturing organizations by measuring the extent of management's interest in internal and external customer and its impact on performance. Petra Engineering Industries Co., applied TQM philosophy and received the King Abdullah II Award for Excellence in the Hashemite Kingdom of Jordan, was selected as a sample for the large industry sector. The company received the abovementioned award for two successive cycles, the second (2001-2002) and the third (2003-2004). A total of (70) questionnaires were distributed, (60) of them were collected (86\%). The study has clearly demonstrated the positive effect of the application of TQM philosophy on improving operational performance with a statistically significant relationship between the management and investment of human capital and improving the performance of employees (internal customer) as well as between the degree of job satisfaction and improving quality of products and low cost of quality. Moreover, this study suggested that there is a statistically significant relationship between the interest of the internal and external customer together and the high percentage of the organization's sales and profits. The study concluded with a set of recommendations, including the need for the management to make every effort to maintain the continuous improvements in order to enhance its competitiveness. The study also recommended that the current salary levels of the employees should be reviewed to be compatible with the high cost of living.

5) Bung-on Chartrungruang et al. (2010), "Customer Satisfaction, Training and TQM: A Comparative Study of Western and Thai Hotels". This study focused on the impact of frontline staff training on improving the quality of hotel services and achieving customers' satisfaction through comparative data from Western and Thai hotels. This study concluded that there was a difference between the services provided in Western and Thai hotels, 
especially in hospitality department, as Thai hotels were lack of the existence of services that suit different customers from different cultures and environments, which affects customers' satisfaction. Therefore, managers should identify appropriate selection and training strategies to enhance guest services, especially in different cultural environments from Thai environment.

\section{Theoretical Framework}

Hotel tourism industry has become one of prominent areas in the tourism development. Hotel industry is a touristic organization that provides a range of services including offering ready rooms and houses by a temporary lease. Hospitality industry relies heavily on human resources, thus it is creating new jobs.

\subsection{The Concept of Hotel Establishment}

Hotel is defined as the organization or the dedicated building licensed to provide accommodation, catering services and all possibilities that the guest requires under local and international laws and for a specific fee and a given period. It also provides other services such as entertainment to the target audience. Hotel management should create good relations with its customers and have qualified technical staff capable of providing services. Hotel is the place where the traveler finds comfort from the hassle of traveling, fun or entertainment for a fixed period and price. The American Hotel \& Motel Association defines it as:" A hostel prepared in accordance with the provisions of the law through which the guest finds shelter, food and other services for a known fee." Hotel can also be seen as a management system designed to work to achieve a specific set of goals.

\subsection{Hotel Features}

A hotel has a range of features that distinguish it from other organizations, namely:

- It is a service organization, containing a number of beds for comfort;

- It is an integrated economic unit, in which complementary services and activities such as marketing, sales, personnel management, financial activity, etc. are carried out to maximize revenue with minimal expenditure;

- It has an independent legal personality;

- It is a complex main system consisting of a set of subsystems, each with distinct functions and different features, most importantly the front office activity and auxiliary departments' activity working together to achieve hotel objectives.

- The goals that it seek to achieve are multiple and different and vary from one hotel to another depending on its type and form, but there are common goals such as providing shelter, food and drink for individuals for a specific fee (Song \& Eitt, 2011).

\subsection{Types of Hotels}

In the world, types of hotels have evolved according to their purposes, objectives and nature. The following are the main types of hotels:

- Permanent Accommodation Hotels: For long stays (e.g., a year), prices are low.

- Transit Hotels: Located in industrial and commercial cities, airports and railway stations, prices are high, space is limited and interest in furnishing is non-existence, short stay for guests.

- Temporary Accommodation Hotels: Is a type of hotel campsite, which is held for a limited period, and for a specific occasion, ending once the event ends such as the International Labor Camp and the Social Volunteer Camp in Ajloun/ Jordan.

- Mobile Hotels: They are established on the surface of water such as floating hotels, or on the surface of earth such as sleeping cabins in trains or caravans pulled by cars.

- Sport Hotels: They are established near stadiums, designed and equipped to serve athletes such as sport cities and Olympic villages.

- Therapeutic Hotels: They are established in certain areas suitable for natural and climatic conditions such as a dry-air hotel for solar treatment and a hotel in a place where mineral and sulfur springs are found for physiotherapy (Gunn, 2008).

- Tourist Hotels: are the most common, suitable prices, they include Motels (small hotels that allow guests to cook in their rooms) and hotels.

- Seasonal Hotels: They are different from permanent hotels and touristic hotels in terms of the quality of guests and the length of stay, but not differ in terms of internal organization and management. They are established on 
snowy mountains or beaches. They should include fun and entertainment means that the guests do not feel bored or tight. The stay period may be long or short in winter and summer.

- Non- traditional means of accommodation. These include the following (Sharply, \& Telfer, 2012):

a- Tourist Villages: It is called the villages of vacations and they are distinguished by their large capacities, which may reach up to 700 rooms or Chalets with low-cost and quick construction. They provide different tourism services. They are established on the shores of seas, in desert or mountainous areas with charming nature, which are attractive to tourists. These hotels are found in Spain, Switzerland, Greece, Turkey and Tunisia.

b- Youth Hostels: They have social and humanitarian objectives such as loyalty, alliance and love among the world has youth, not for profit, monitored and managed by Youth Hostel International Federation including both genders, distinguished by its cheap prices and spread throughout the world with excellent level of services.

c- Camps: Spread over the past 25 years in desert and mountainous areas, river and seashores and in places with great nature and tourist attractions and civilization.

\subsection{The Quality of Hotel Services}

\subsubsection{The Concept of Quality of Hotel Services}

Service is defined as an activity or a series of activities that are nearly intangible and unusual. In addition, a service is an economic activity, which creates a value and provides benefits to customers in a specific time and place to achieve a desired change in favor of the service beneficiary. Judd defined a service as an exchange operation that an institution carried out, where the object of exchange does not transfer the ownership of a material object to the other party. Kotler suggested that a service is any activity, performance or utility provided by one party to another, is essentially intangible, and does not result in ownership, and that its production or supply may be related to a tangible product (Hsu \& Pors, 2008, p. 297).

Hotel service is a group of activities and operations, which are provided by a hotel management and employees to the guests and through the use of tangible goods often. These intangible activities offered by a hotel organization to the guests in such a way that gives them satisfaction, acceptance and use as well as influences them to visit the hotel again.

\subsubsection{Elements of the Quality of Hotel Service}

Hotel service has three important complementary elements (Hsu \& Pors, 2008, p. 297):

- Core service: The comprehensive and basic function for which the hotel was found is the accommodation (overnight stay);

- Facilitation services: are necessary services for the continuous operations of a hotel, without such services, it becomes impossible to deliver or provide the main benefit in a hotel that the absence of reception may lead to failure of the hotel work. The facilitation goods are also essential for the success of the service. For example, the appropriate towels and furniture are necessary for the hotel as these services are found to facilitate the tourist's stay.

- Support services: services that are not necessary but support the marketing function in a hotel and leads to distinguish a hotel from other competitors. For example, restaurant is not a necessary component of a hotel, but its presence in a hotel distinguishes it from other hotels, as well as transport services and touristic programs organized by a hotel.

\subsubsection{Features of the Quality of Hotel Service}

The features of the hotel services can be summarized by:

- Most of them are intangible because they represent experiences and intellectual knowledge that are difficult to quantify physically;

- Customers of services are characterized by the fact that they receive the services they require at their place of production;

- Customers can access these services directly or indirectly through specialized intermediaries such as transport, catering and other services.

- Customers consume these services as soon as they are received and cannot store or keep them;

- These services cannot be stereotyped; they are always variable and varied as they relate to what each customer requires. 
(Brwwke \& Buckley, 2008)

It should be noted that it is difficult to provide a precise definition for the quality, but it is based on two basic concepts:

- Entrepreneurship: providing developed renewable touristic services to meet the needs of tourist;

- Excellence: balancing the requirements of the tourist and the hotel's general components, in the sense of raising the level of employees performance in the hotel ('Béatrice Brechignac-Roubaud, 2013; Philip \& Kotler, 2016)

\subsubsection{Dimensions of the Quality of Hotel Service}

The quality of hotel services has a set of dimensions: (Chistopher H. \& Lovelock, 2006, Paker \& Pardley \& Geremy, 2004).Reliability, Tangibles, Telecommunications , Credibility, Understanding and knowing the customer ,Safety ,Ability ,Easy access to the service ,Courtesy ,Response .

\subsubsection{Factors Affecting Quality of Hotel Service}

There are several factors that affect the quality of hotel service (Manuela Pulina, 2013): Customer expectations analysis, determining the quality of services, internal customer performance.

\subsubsection{The Quality in Jordanian Hotels}

The quality plan for tourism in Jordan related to hotels has included several criteria and conditions for the implementation of quality in hotels. This will be in various stages of service delivery:

- Media and communication: includes giving clear information, an adequate effective policy and placing a signboard and shop address;

- Reception includes personal reception and hospitality, politeness, courtesy, warmth and smiling at reception.

- Users' efficiency includes: serve customers quickly, advice and wisdom, access to and examine adopted information and control foreign languages;

- Control places includes: maintenance and cleanliness, plants and green spaces, reception and comfort places and comfortable furnishing;

- Maintenance and cleanliness of places include cleanliness and hotel facilities with good conditions.

- Giving a value for local resources includes emphasis on local dishes, informing tourists about the benefits of exploring the region.

\subsection{The Fundamentals of the Tourism Industry in Jordan}

In the twentieth century, tourism industry became one of the most important phenomena that this century was called the "Century of Tourism". The twenty-first century is the "century of tourism industry" because tourism industry will be the largest industry. Jordan is characterized by its many different touristic fundamentals, which are used as an important tourism attraction. The following are the most important tourism fundamentals in the Hashemite Kingdom of Jordan and its role in attracting tourists:Terrain,Moderate climate ,Historical, archaeological and urban fundamentals: Jordan has many important historical and archaeological sites, which are distinguished internationally, Fundamentals such as the Shrine of Jaafar and the Shrine of Zaid in al-Karak city ,Natural fundamentals: they are attraction and marketing factors for Jordan, including moderate climate throughout the year ,Security and stability factors ,Social factors and Jordanian citizen ,Integrated tourism services and facilities ,Multiple types of tourism available in Jordan ,Free economic system.

\subsection{The Marriott International Hotel in Amman}

The Marriott International Hotel in Amman is a five-star establishment, located in Shmeissani/ Amman, just a few steps from the cultural and historical landmarks of Jordan. It offers a modern accommodation in the old country. Due to the hotel's features and its location, it is the most suitable choice for business and social actions. In addition to the hotel's qualified staffs that are always ready to meet guests' needs, it has some restaurants and bars, so you have many options, depending on your mood, such as "Champions Sports Bar and Restaurant" for those seeking an informal atmosphere, and "Piano Lounge" for those looking for classy environment to drink coffee or tea and eat some delicious sweets. If you are looking for delicious food, cigar and wine do not miss the opportunity to visit "Award Winning Library Lounge" and Cigar Bar". If this does not suit your appetite for the evening, you can take a walk out and choose what suits you from restaurants like the Italian restaurant, "Romeo", "Harit Jdoudna" or "The Living Room". The hotel also has two swimming pools and a sauna and steam room, 
making it ideal for a variety of beauty treatments. The newly refurbished rooms of the hotel are luxuriously decorated in a modern style. These rooms are spacious and comfortable for the visitor after a hard day in the city or business meetings. In addition, some rooms have beautiful panoramic views. The hotel is considered ideal for business travelers due its strategic location in the business district, and it is close to business centers and tourism sites. The spacious rooms at the hotel are well designed for comfort and work. Moreover, the hotel provides international cuisine, a traditional library, a cigar lounge, a gymnasium, swimming pools, business services, a childcare center, fast internet connection and much more. The hotel's lounge is the ideal venue for wedding and conferences, which can accommodate up to 500 people.

\section{Data Analysis}

\subsection{Analysis of the Items and Questions of the Study's Instrument}

Statistical analysis of the views of the sample of internal customers at the Amman Marriott International Hotel:

Table 3. The arithmetic means and standard deviations of the independent variable items and questions

\begin{tabular}{|c|c|c|c|c|c|c|}
\hline \multicolumn{7}{|c|}{ Independent Variable: dimensions of internal customer's role } \\
\hline No & paragraphs & $\begin{array}{l}\text { Arithmetic } \\
\text { Mean }\end{array}$ & $\begin{array}{l}\text { Standard } \\
\text { deviation }\end{array}$ & $\begin{array}{l}\text { t } \\
\text { Value } \\
\end{array}$ & Sig. & $\begin{array}{l}\text { Answers } \\
\text { Trends }\end{array}$ \\
\hline 1 & $\begin{array}{l}\text { Your hotel is keen to attract and select individuals specialized in hotel } \\
\text { services. }\end{array}$ & 3.84 & 0.621 & 46.729 & 0.000 & High \\
\hline 2 & Your hotel selects applicants to work according to the required skills & 3.63 & 0.919 & 29.845 & 0.000 & High \\
\hline 3 & $\begin{array}{l}\text { Your hotel is interested in developing communication means among } \\
\text { employees to facilitate their work. }\end{array}$ & 3.21 & 0.940 & 25.788 & 0.000 & Medium \\
\hline 4 & Your hotel reduces barriers between staff and senior management. & 3.40 & 0.942 & 27.271 & 0.000 & High \\
\hline 5 & $\begin{array}{l}\text { Your hotel seeks to coordinate the activities of staff in a way that helps } \\
\text { to achieve cooperation among them. }\end{array}$ & 3.56 & 0.780 & 34.490 & 0.000 & High \\
\hline 6 & $\begin{array}{l}\text { Your hotel cares about the satisfaction of employees by meeting their } \\
\text { needs and desires. }\end{array}$ & 3.14 & 0.972 & 24.399 & 0.000 & Medium \\
\hline 7 & $\begin{array}{l}\text { Your hotel make changes to employees' attitudes and beliefs to suit the } \\
\text { level of quality required.. }\end{array}$ & 3.77 & 0.780 & 36.528 & 0.000 & High \\
\hline 8 & $\begin{array}{l}\text { Your hotel is keen to enable employees to present their ideas and } \\
\text { suggestions for the development of hotel services provided. }\end{array}$ & 3.61 & 1.048 & 26.035 & 0.000 & High \\
\hline 9 & $\begin{array}{l}\text { Your hotel is interested in organizing training courses for staff to } \\
\text { improve the quality of services provided to customers. }\end{array}$ & 3.58 & 0.905 & 29.847 & 0.000 & High \\
\hline 10 & $\begin{array}{l}\text { Your hotel encourages creativity and providing initiatives aim to } \\
\text { improving the quality of service provided. }\end{array}$ & 4.21 & 0.750 & 42.403 & 0.000 & $\begin{array}{l}\text { Very } \\
\text { High }\end{array}$ \\
\hline 11 & $\begin{array}{l}\text { Your hotel is keen to reward employees for the quality of services } \\
\text { provided }\end{array}$ & 2.96 & 1.149 & 19.482 & 0.000 & Medium \\
\hline 12 & $\begin{array}{l}\text { Your hotel is interested in involving employees in the decision making } \\
\text { process related to the development of the quality of services provided. }\end{array}$ & 2.96 & 1.210 & 18.506 & 0.000 & Medium \\
\hline 13 & $\begin{array}{l}\text { Your hotel gives the necessary authority for employees to perform the } \\
\text { tasks. }\end{array}$ & 3.65 & 0.744 & 37.039 & 0.000 & High \\
\hline 14 & $\begin{array}{l}\text { The employees solve the problems they encounter without referring to } \\
\text { the officials. }\end{array}$ & 3.58 & 0.885 & 30.520 & 0.000 & High \\
\hline 15 & $\begin{array}{l}\text { Your hotel is keen to encourage employees to provide high quality } \\
\text { services. }\end{array}$ & 3.19 & 1.008 & 23.920 & 0.000 & Medium \\
\hline 16 & $\begin{array}{l}\text { Your hotel is interested in promoting trustful relationships among } \\
\text { employees. }\end{array}$ & 3.56 & 1.035 & 25.969 & 0.000 & High \\
\hline 17 & $\begin{array}{l}\text { Your hotel is keen to show the suitable and attractive appearance of } \\
\text { staff. }\end{array}$ & 4.02 & 0.719 & 42.162 & 0.000 & High \\
\hline Total & & 3.52 & 0.475 & 56.047 & 0.000 & High \\
\hline
\end{tabular}

Source: prepared by the researchers based on SPSS Version 19.

Analysis of the responses of the sample in relation to the independent variables; the interest of the hotel management to improve the level and the meeting of the internal customers' needs: It is clear from the previous table that the responses were close and with high arithmetic means, ranging from the highest value of 4.21 to the highest of 10 , with a standard deviation of 0.750 , and the lowest mean of paragraphs 11 and 12 with a value of 2.96, with standard deviations 1.149 and 1.210 respectively. As shown in the same table, the arithmetic mean for all items of the internal customer interest is high at 3.52 , a standard deviation of 0.475 , and the probability value 
of $\operatorname{Sig}=0,000$ is statistically of significance at a level of 0.05 . Since $(t)$ value of 56,047 indicates that the mean response to this paragraph has exceeded the level of neutrality 3 , which means that the degree of approval is high, from the sample on this axis, which reflects that the hotel interest in relation to treating employees as internal customers to achieve its objectives.

Table 4. The arithmetic means and standard deviations of the dependent variable items and questions

\begin{tabular}{|c|c|c|c|c|c|c|}
\hline \multicolumn{7}{|c|}{ The dependent variable: Improving the quality of hotel services } \\
\hline No & paragraphs & $\begin{array}{l}\text { Arithmetic } \\
\text { Mean }\end{array}$ & $\begin{array}{l}\text { Standard } \\
\text { deviation }\end{array}$ & $\begin{array}{ll}\mathbf{t} \\
\text { Value }\end{array}$ & Sig. & $\begin{array}{l}\text { Answers } \\
\text { Trends }\end{array}$ \\
\hline 18 & $\begin{array}{l}\text { Your hotel seeks to excel at a high level of quality compared to its } \\
\text { competitors. }\end{array}$ & 3.56 & 0.982 & 27.373 & 0.000 & High \\
\hline 19 & Your hotel identify and study the needs and desires of its customers. & 3.74 & 0.835 & 33.784 & 0.000 & High \\
\hline 20 & $\begin{array}{l}\text { Your hotel cares about the quality of services provided to satisfy its } \\
\text { customers. }\end{array}$ & 3.70 & 0.981 & 28.479 & 0.000 & High \\
\hline 21 & $\begin{array}{l}\text { Your hotel is keen to cooperate with employees to meet the needs and } \\
\text { desires of its customers. }\end{array}$ & 3.44 & 0.780 & 33.300 & 0.000 & High \\
\hline 22 & $\begin{array}{l}\text { Your hotel is interested in providing new services to the customer } \\
\text { continuously. }\end{array}$ & 3.25 & 0.872 & 28.107 & 0.000 & Medium \\
\hline 23 & $\begin{array}{l}\text { Your hotel is interested in predicting the numbers of guests to } \\
\text { provide quality services to meet their needs. }\end{array}$ & 3.37 & 0.816 & 31.176 & 0.000 & Medium \\
\hline 24 & $\begin{array}{l}\text { Your hotel makes sure that the design of the hotel is consistent with } \\
\text { the type of service provided. }\end{array}$ & 3.14 & 0.934 & 25.378 & 0.000 & Medium \\
\hline 25 & $\begin{array}{l}\text { Your hotel cares about the timeliness of service delivery to its } \\
\text { customers. }\end{array}$ & 3.60 & 0.821 & 33.085 & 0.000 & High \\
\hline 26 & Your hotel is continuously improving the services provided. & 3.74 & 0.768 & 36.723 & 0.000 & High \\
\hline 27 & $\begin{array}{l}\text { Your hotel fulfils the promises made to customers by providing the } \\
\text { advertised services, thereby enhancing customers' satisfaction. }\end{array}$ & 3.86 & 0.718 & 40.579 & 0.000 & High \\
\hline 28 & $\begin{array}{l}\text { Your hotel is characterized by a high degree of accuracy and quality } \\
\text { when accomplishing the services provided to its customers. }\end{array}$ & 3.65 & 0.991 & 27.804 & 0.000 & High \\
\hline 29 & $\begin{array}{l}\text { Your hotel is keen to compare the quality of service provided to its } \\
\text { customers with its competitor in order to develop it. }\end{array}$ & 3.60 & 0.904 & 30.051 & 0.000 & High \\
\hline 30 & $\begin{array}{l}\text { Your hotel depends on teamwork as a way to improve the quality of } \\
\text { the services provided. }\end{array}$ & 3.33 & 0.932 & 26.996 & 0.000 & Medium \\
\hline 31 & $\begin{array}{l}\text { Your hotel takes into consideration the opinions of employees when } \\
\text { making changes aim to improving the quality of the services } \\
\text { provided. }\end{array}$ & 3.21 & 1.161 & 20.879 & 0.000 & Medium \\
\hline 32 & $\begin{array}{l}\text { Your hotel shows an interest in solving the problems your customers } \\
\text { face. }\end{array}$ & 3.54 & 0.946 & 28.276 & 0.000 & High \\
\hline 33 & $\begin{array}{l}\text { Your hotel uses guest complaints to benefit from to improve the } \\
\text { quality of services and to design new services. }\end{array}$ & 3.61 & 1.098 & 24.851 & 0.000 & High \\
\hline 34 & $\begin{array}{l}\text { Your hotel is interested in adopting the most recent working } \\
\text { methods in hotel industry. }\end{array}$ & 3.44 & 1.165 & 22.280 & 0.000 & High \\
\hline 35 & $\begin{array}{l}\text { Your hotel is keen to use the latest technology used in the service } \\
\text { delivery process. }\end{array}$ & 3.75 & 1.005 & 28.208 & 0.000 & High \\
\hline Total & & 3.53 & 0.542 & 49.169 & 0.000 & High \\
\hline
\end{tabular}

Source: prepared by the researchers based on SPSS Version 19.

Analysis of the responses of the sample members in relation to the dependent variable; the interest of the hotel management to improve the quality of hotel services: It is clear from the previous table, that the responses of the respondents were close and with the arithmetic means, which were mostly high, ranging from the highest of 3.86 to 27 , with a standard deviation of 0.718 , and between the lowest mean for paragraph 24 , with a value of 3.14 , and a standard deviation of 0.934 . The mean for all paragraphs of improving the quality of hotel services axis is high by 3.53 , with a standard deviation of 0.542 , and the probability value of $\mathrm{Sig}=0.000$. This means, that it is of statistical significant at a level of 0.05 . Since $(t)$ is 49.169 , indicates that the mean response to this paragraph has increased the neutrality of 3 , which means that the approval degree by the members of the sample is high on this axis, which reflects that the hotel cares about improving the quality of its services provided, which enables it to excel compared to its competitors. 


\subsection{Hypotheses Test}

The first hypothesis test: There is no significant role at $(\alpha=0.05)$ for the internal customer with its dimensions (selection and training, motivation, participation in decision-making) in improving the quality of hotel services provided at Amman Marriott International Hotel.

At a significant level of 0.05 , we calculated the arithmetic mean and $(t)$ value to test this hypothesis.

Table 5. The arithmetic means and $t$ test of the first hypothesis

\begin{tabular}{|c|c|c|c|c|c|c|}
\hline Coefficient of Correlation & $\mathrm{R}$ & & 0.776 & & & \\
\hline Coefficient of Determination & $\mathrm{R}^{2}$ & & 0.603 & & & \\
\hline F value: 83.520 & Significance Level 0.000 & & & $\alpha=0.05$ & & \\
\hline \multirow[t]{2}{*}{ The Variable } & & \multicolumn{2}{|c|}{$\begin{array}{l}\text { Non-standard } \\
\text { transactions }\end{array}$} & $\begin{array}{l}\text { Standard } \\
\text { transactions }\end{array}$ & $\begin{array}{l}\text { Value Of } \\
\mathrm{t}\end{array}$ & $\begin{array}{l}\text { Significance } \\
\text { Level }\end{array}$ \\
\hline & & $\beta$ & $\begin{array}{l}\text { Standard } \\
\text { Error }\end{array}$ & Beta & & \\
\hline \multirow{2}{*}{\multicolumn{2}{|c|}{$\begin{array}{l}\text { Independent variable: (dimensions of internal customer). } \\
\text { Dependent variable: (improving the quality of hotel } \\
\text { services). }\end{array}$}} & 0.406 & 0.345 & 0.776 & 1.176 & 0.245 \\
\hline & & 0.886 & 0.097 & & 9.131 & 0.000 \\
\hline
\end{tabular}

Source: prepared by the researcher based on SPSS Version 19 .

The table shows that the coefficient of determination $\left(\mathrm{R}^{2}\right)$ is 0.603 , which indicates to explain the independent variable represented in the internal customer to the dependent variable is $60 \%$, and that the remaining $40 \%$ of the effect in the dependent variable is due to other factors besides the random error. Also, the value of $(\mathrm{F})$ that reached 83.520 at $95 \%$ confidence level to the regression line for the correlation between the independent variable and the dependent variable regression line. The 'correlation coefficient $\mathrm{R}$ value of 0.776 indicates a strong positive relationship between the two variables. The level of significance for the independent variable is 0,000 , which is less than the significance level of 0.05 , which indicates its statistical significance. This indicates the importance of this variable in interpreting the dependent variable. Therefore, we can accept the alternative hypothesis which states that there is a correlation of statistical significance at the level of significance $5 \%$ between the interest in the internal customer needs and the improvement of the quality of hotel services. From the abovementioned, we deduce the following simple regression equation:

$$
\mathrm{Y}=\mathrm{a}+\mathrm{b} \mathrm{X}+\varepsilon_{i}
$$

Improving the quality of hotel services $=0.406+0.887$ the internal customer

First sub-hypothesis test: There is no significant role at $(\alpha=0.05)$ for training internal customer in improving the quality of hotel services at Marriott International Hotel in Amman. At a significant level of 0.05, we calculated the arithmetic mean and $(\mathrm{t})$ value to test this hypothesis.

Table 6. The arithmetic mean and the (t) test for the first sub- hypothesis

\begin{tabular}{lllll}
\hline Variable & $\begin{array}{l}\text { Arithmetic } \\
\text { Mean }\end{array}$ & $\begin{array}{l}\text { Standard } \\
\text { Deviation }\end{array}$ & $(\mathrm{t})$ & $\begin{array}{l}\text { Significance } \\
\text { Level }\end{array}$ \\
\hline Selecting and training the internal customer & 3.52 & 0.475 & 56.047 & 0.000 \\
\hline
\end{tabular}

Source: prepared by the researcher based on SPSS Version 19.

Results showed that the arithmetic mean of the responses of the expressions forming this theme is 3.52 and with a deviation of 0.475 . Since the calculated $(\mathrm{t})$ value is 56.047 , which is larger than its tabular value, this leads to the rejection of the null- hypothesis, and acceptance of the alternative hypothesis. The calculated significance of 0.000 was less than 0.05 , which is less than the approved level. This confirms the rejection of the nullhypothesis and the acceptance of the alternative hypothesis. Therefore, the management of the Marriott International Hotel is concerned with improving the level and meeting the internal customer needs.

Second sub-hypothesis test: There is no significant role at $(\alpha=0.05)$ for motivating the internal customer in improving the quality of hotel services at Marriott International Hotel in Amman. At a significant level of 0.05, the arithmetic mean and $(\mathrm{t})$ value were calculated to test this hypothesis. 
Table 7. The arithmetic mean and the (t) test for the second sub- hypothesis

\begin{tabular}{lllcc}
\hline Variable & $\begin{array}{l}\text { Arithmetic } \\
\text { Mean }\end{array}$ & $\begin{array}{l}\text { Standard } \\
\text { Deviation }\end{array}$ & (t) & $\begin{array}{c}\text { Significance } \\
\text { Level }\end{array}$ \\
\hline Motivating the internal customer & 3.53 & 0.542 & 49.169 & 0.000 \\
\hline
\end{tabular}

Source: prepared by the researcher based on SPSS Version 19.

The results of the table above show that the mean arithmetic of the responses of the items that constitute the extent of attention to the outstanding performance reached 3.53 with a deviation of 0.542 . Since the calculated value of $(t)$ is 49.169 , which is greater than its tabular value, this leads to rejection the null- hypothesis and acceptance of the alternative hypothesis. The result is confirmed by the significance level of 0.000 that was less than 0.05 , and less than the approved level. This confirms the rejection of the null- hypothesis and the acceptance of the alternative hypothesis. Therefore, the management of the Marriott International Hotel is concerned with improving the quality of the services provided to increase its performance.

Third sub-hypothesis test: There is no significant role at $(\alpha=0.05)$ for the participation of internal customer in decision-making in improving the quality of hotel services at Marriott International Hotel in Amman. At a significant level of 0.05 , the arithmetic mean and $(\mathrm{t})$ value were calculated to test this hypothesis.

Table 8. The arithmetic mean and the $(\mathrm{t})$ test for the third sub- hypothesis

\begin{tabular}{lllll}
\hline Variable & $\begin{array}{l}\text { Arithmetic } \\
\text { Mean }\end{array}$ & $\begin{array}{l}\text { Standard } \\
\text { Deviation }\end{array}$ & $\begin{array}{c}\text { (t) } \\
\text { Level }\end{array}$ \\
\hline Participation of the internal customer in decision-making & 3.87 & 0.433 & 55.347 & 0.000 \\
\hline
\end{tabular}

Results of the above table show that the arithmetic mean of the responses of interesting in a distinguished performance is 3.87 and a deviation of 0.433 , where the calculated value of $(t)$ is 55.347 , which is greater than its tabular value. This led us to reject the null hypothesis and accept the alternative one. This result can be affirmed by the fact that the significance level of 0.000 was less than 0.05 , which is less than the approved level. Therefore, the management of Marriott International Hotel is concerned with improving the quality of the services provided to increase its performance.

\section{Results and Recommendations}

\subsection{Results}

The present study concluded to several findings that could improve the internal customer's role at the Marriott International Hotel in Amman and the quality of hotel services provided to the external customer. The most prominent of these findings are the following:

- Tourism in Jordan is no longer a choice, but a national necessity to achieve tourism development that contributes to economic growth.

- Jordan, as a touristic destination, is still weak and does not even reach to the levels of tourism within the destinations of Mediterranean basin region.

- In Jordan, tourism services are still weak and deficient and quantitatively.

- In Jordan, communication and marketing programs for tourism destinations are ineffective and does not adapt to various developments.

- In Jordan, statistical figures of tourism are considered the weakest in the Mediterranean Basin region, which explains the symbolic tourism revenues in Jordan.

- Hotel sector in Jordan suffers from several weaknesses, the most prominent of which are:

- Hotel capacity is inadequate and lacks quality.

- Hotel structure does not meet international standards and needs to be significantly reformulated.

- Poor hotel services.

- The weakness of the composition of employees in the hotel sector has affected their levels of performance of services provided. 
- There is an interest of the management of Amman Marriott International Hotel to internal customers to determine its future policies and priorities. This is reflected in the answers of respondents.

- The management of Amman Marriott International Hotel provides various services to customers.

- The hotel officials set up a work route to ensure the good implementation for hotel's activities and services provided.

- The hotel management is concerned with internal customers that it highlights their value as internal customers by satisfying their various needs and desires, as demonstrated by the first hypothesis test.

- The hotel is keen to encourage its employees to exchange information and experience among themselves in order to improve their performance of the services provided, and is keen to develop their skills through providing training programs that contribute to raise their abilities to improve the quality of services provided, which was shown by testing the second hypothesis.

- The Marriott International Hotel is concerned with the implementation of the internal customer concept as a way to satisfy the external customer through fulfilling the promises made by providing high quality hotel services. This is demonstrated by the third hypothesis test, which indicates a significant relationship at a significant level of $5 \%$ between meeting the internal customer's needs and the quality of hotel services.

\subsection{Recommendations}

- There is a need to develop staff knowledge and skills in terms of interest in internal customer and gain a future vision to determine their needs of human resources.

- The Marriott International Hotel should conduct specialized training courses on the subject of providing high quality hotel services in order to increase the awareness of internal customers and ensure that they carry out this process in the correct manner and practical steps.

- There is a need to actively involve the internal customers in making decisions and motivate them to work.

- There is a need for the hotel management to depend on the internal customers to examine the actual internal conditions of the hotel, to analyse their knowledge and awareness and to assess their performance.

- There is a need to analyse the external environment in order to identify the strengths and weaknesses, compared to other hotels to create a strategic plan that will improve the quality of services provided and the formulation of future policies.

- There is a need to work to benefit from the experience of other hotels, which actually practice indicators to improve and measure the quality of services provided systematically and scientifically.

- There is a need for hotel's management to develop indicators to frequently measure the quality of services provided by internal customers and to adopt clear and written systems for monitoring and evaluation.

\section{References}

Ahmed, A. S., \& Majda, A. (2008). The Impact of the Application of The Philosophy of Total Quality Management According to the Internal and External Customer's Perspective on the Operational Performance of the Manufacturing Organizations (A case Study of Petra Engineering Industries In Jordan). Journal of Management and Economics, 73, 73-96. Mustansirya University,

Bouanan, N. (2007). The Quality of Services and its impact on Customers' Satisfaction: Field Study at the Enterprise Port of Skikda. Faculty of Economic, Administrative and Commercial Sciences, Mohammed Boudiaf University, Algeria, Master Thesis, published.

Brwwke, G., \& Buckley, M. (2008). To manager of international tourism. London: Pitman,

Christopher, H. L. (2006). Service Marketing (3rd edition). New Jersey: Prentie Hill, inc.

Christopher, L. et al. (2008). Marketing Des Services (6th edition, p. 12). Pearson education France.

Gunn, C. A. (2008). Tourism planning (2nd edition). New York: Taylor \& Francis.

Hsu, K., \& Poser, T. (2008). Translated by Sorour Ibrahim Sorour, Hospitality Marketing, Dar Al-Marikh for Publishing and Distribution, Saudia Arabia, p. 297.

Manuela, P. (2013). Quantities forecasting for tourism: nel, ols, and arima x approaches, university of Sassari and crenos, Italy.

Paker, P., \& Germy. (2004). Principles of Hotel Management, Cassel Educational Limit. 
Sharply, R., \& Telfer, D. (2012). Tourism and development, concepts and issues, channel view publication, Cleve don.

Song, H., \& Eitt, F. (2011). Tourism demand modeling and forecasting: Modern Econometric Approaches, Pregame: Oxford.

Sulaiman AL-Khataab et al. (2016). The Impact of the Relationship between the Quality of Internal and External service and Internal Customer Satisfaction as a Modified Variable: A study on a sample of Restaurants with Full Services in Amman. Dirasat Journal, 43(1), 43-60. University of Jordan- Deanship of Scientific Research, Amman, Jordan.

\section{Copyrights}

Copyright for this article is retained by the author, with first publication rights granted to the journal.

This is an open-access article distributed under the terms and conditions of the Creative Commons Attribution license (http://creativecommons.org/licenses/by/4.0/). 